
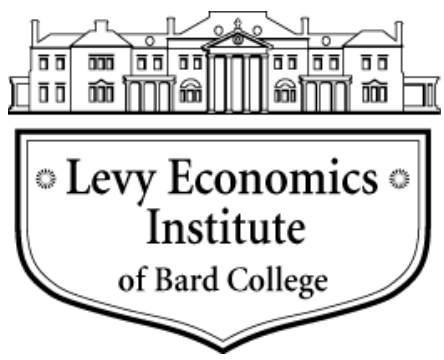

Working Paper No. 897

\title{
Quantitative Easing and Asset Bubbles in a Stock-flow Consistent Framework
}

by

Cameron Haas

Bard College at Simon's Rock

Tai Young-Taft

Levy Economics Institute of Bard College and Bard College at Simon's Rock

\section{September 2017}

The authors would like to thank their discussant, Gregor Semieniuk, and Michael Ehrlich and Duncan Foley from the audience at the 43rd Conference of the Eastern Economics Association for valuable feedback when this paper was presented.

The Levy Economics Institute Working Paper Collection presents research in progress by Levy Institute scholars and conference participants. The purpose of the series is to disseminate ideas to and elicit comments from academics and professionals.

Levy Economics Institute of Bard College, founded in 1986, is a nonprofit, nonpartisan, independently funded research organization devoted to public service. Through scholarship and economic research it generates viable, effective public policy responses to important economic problems that profoundly affect the quality of life in the United States and abroad.

Levy Economics Institute

P.O. Box 5000

Annandale-on-Hudson, NY 12504-5000

http://www.levyinstitute.org

Copyright (C Levy Economics Institute 2017 All rights reserved

ISSN 1547-366X 


\begin{abstract}
Ever since the Great Recession, central banks have supplemented their traditional policy tool of setting the short-term interest rate with massive buyouts of assets to extend lines of credit and jolt flagging demand. As with many new policies, there have been a range of reactions from economists, with some extolling quantitative easing's expansionary virtues and others fearing it might invariably lead to overvaluation of assets, instigating economic instability and bubble behavior. To investigate these theories, we combine elements of the models in chapters 5,10 , and 11 of Godley and Lavoie's (2007) Monetary Economics with equations for quantitative easing and endogenous bubbles in a new model. By running the model under a variety of parameters, we study the causal links between quantitative easing, asset overvaluation, and macroeconomic performance. Preliminary results suggest that rather than being pro- or countercyclical, quantitative easing acts as a sort of phase shift with respect to time.
\end{abstract}

KEYWORDS: Quantitative Easing; Stock-flow Consistency; Macroeconomics

JEL CLASSIFICATIONS: E12; E44; E58; E16; E21 


\section{INTRODUCTION}

In this paper, we will create a stock-flow consistent (SFC) model to investigate the relationship between quantitative easing and economic instability. We start by summarizing quantitative easing and referencing some of the literature discussing similar issues. Then the balance sheets of our model are presented, as rigorous accounting is a key component of SFC modeling. The model's equations follow, as well as an analysis of simulation results. We conclude by discussing possible ways to improve the model herein and briefly mentioning the policy implications of our results.

\section{LITERATURE REVIEW}

Before the Great Recession, most analysis of central bank activity considered only their ability to set the short-term interest rate. In a 1993 paper, J. B. Taylor famously argued that discretionary monetary policy was inefficient and a fixed policy rule that made the interest rate a function of inflation and the output gap would result in optimal macroeconomic outcomes (Taylor 1993). It was not long before this rule was put to the test when the Bank of Japan's (BOJ) interest rate plummeted to zero in the early 2000s in response to endemic deflation (Fujii and Kawai 2010). With interest rates so near zero, the BOJ could no longer influence economic outcomes through interest rate adjustment alone, as conventional wisdom at the time stipulated that negative interest rates were impossible (though intervening years proved even this assumption wrong). The BOJ proposed a new policy of quantitative easing, where the central bank would create reserves to buy assets in the open market, enlarging the monetary base and hopefully jolting demand. Initial analysis judged that short of changing expectations, such activity would be irrelevant once equilibrium was achieved (Eggertson and Woodford 2003).

Despite these theories, by the end of the decade, quantitative easing was a widely established policy. The crash of the mortgage-backed security (MBS) market forced the US Federal Reserve to buy a trillion dollars of toxic MBSs lest the economy's liquidity continue to deteriorate (Mehrling et al. 2013). A similar policy was undertaken by the Bank of England, which bought 
200 billion pounds of gilts (long-term government bonds) from households to ease credit conditions (Joyce et al. 2011).

With the policy of quantitative easing newly ascendant, economists leaped to a variety of conclusions. Some argued that even if the monetary base were increased, its conversion into money supply would be gradual in a depressed economy, thus preventing uncontrollable inflation (Bullard 2010). Others were less sanguine about the impacts of quantitative easing. Empirical studies have shown that quantitative easing has accelerated the flow of capital into less economically developed countries beyond reasonable bounds (Fratzscher, Lo Duca, and Straub 2013). From within the Keynesian paradigm, quantitative easing was criticized on the grounds that with long-term bonds removed from their portfolios, investors would spend too much in other areas, which could lead to the overvaluation of certain assets and the associated bubble behavior (Palley 2011).

There have been attempts within the dynamic stochastic general equilibrium (DSGE) literature to model the behavior of bubbles and their role in creating economic instability (see Hirano and Yanagawa 2015). In these models, bubbles are generally the result of random exogenous shocks rather than endogenous byproducts of the fundamental instability that Minskyians argue is part of a complex monetary system (Minsky 1992). In an attempt to explore the relation between quantitative easing and asset bubbles, we have created a model with exogenous quantitative easing and endogenous bubble behavior (where equity booms are burst by panics), following the SFC modeling approach of Godley and Lavoie (2007). This was a natural choice, as SFC models generally have more clearly articulated financial systems and we are skeptical of the behavioral basis of a representative agent maximizing utility into perpetuity.

\section{BALANCE SHEETS AND THE TRANSACTIONS-FLOW MATRIX}

Before proceeding, we briefly summarize our notation. Subscripts are used to identify a variable with: a particular sector, demand or supply characteristics, a particular financial instrument, or a particular time period. Subscripts, in turn, identifying a sector with a variable are: households (h), the central bank (cb), and firms (f). As for financial instruments we have: equities (e), long- 
term government bonds (bL), and bills (b), while (d) identifies a variable as demand side and (s) as supply side.

Finally, the subscript -1 means that the variable's value in the last period is being used. If there are multiple subscripts they all apply to that variable without commas separating them. The ordering of the subscripts goes as follows: demand/supply, identity, time lag.

Superscripts are used more sparingly: e means that a variable is an expected value and T means it is a target value that may not be met. ${ }^{1}$ Any parameters and or variables will be named as we describe the model's equations.

\section{Table 1: Balance Sheet}

\begin{tabular}{c|c|c|c|c|c} 
& Households & Firms & Government & Central Bank & $\Sigma$ \\
\hline Money & $+H$ & & & $-H$ & 0 \\
Bills & $+B_{h}$ & & $-B$ & $+B_{c b}$ & 0 \\
Bonds & $+p_{b L} \cdot B L_{h}$ & & $-p_{b L} \cdot B L_{s}$ & $+p_{b L} \cdot B L_{c b}$ & 0 \\
Equities & $+p_{e} \cdot e_{d}$ & $-p_{e} \cdot e_{d}$ & & & 0 \\
Net Worth & $-V$ & $+i n$ & $+\left(V-p_{e} \cdot e_{d}\right)$ & & 0 \\
\hline \hline$\Sigma$ & 0 & 0 & 0 & 0 & 0
\end{tabular}

As articulated by Godley and Lavoie (2007), any model of a closed economy must be balanced both intra- and intersectorally. Our balance sheet represents this by recording assets as positive numbers, liabilities as negative numbers, and stipulating that every row (which represents an intersectoral obligation) and column (which represents a sector) sum to zero. This is a formalization of the accounting requirements that one agent's asset must be another's liability and that accounts always balance. In our economy, households (and central banks, to an extent) can choose to invest in four different classes of assets: money (H), short-term government bills (B), long-term government bonds (BL), and equities (e).

Money has an interest rate of zero but is still held for its liquidity. This is an asset for households, who use it for transactions and as a store of wealth, and a liability for central banks

\footnotetext{
${ }^{1}$ We replicate the notation used in Godley and Lavoie's (2007) Monetary Economics insofar as possible to facilitate cross referencing.
} 
who must uphold its value if pressed. Bills are government liabilities issued to finance spending and pay interest at rate $\left(\mathrm{r}_{\mathrm{b}}\right)$ each period, which is set exogenously and is assumed to be determined by the central bank. Both households and central banks hold bills.

Long-term government bonds (BL) are consols - that is, pieces of paper that entitle their holder to one unit of currency in revenue into perpetuity. Since their price changes over time, we multiply all terms in the bonds row by price $\left(\mathrm{p}_{\mathrm{bL}}\right)$. Households are the primary holders of longterm bonds, but during quantitative easing regimes central banks might hold bonds as well.

Our model does not assume that markets always clear or that economic agents have perfect information, and thus to ensure they can always meet demand, firms accumulate inventories. However, in an SFC model all accounts must balance, so we introduce the corresponding liability equities. Holders of equities are entitled to a certain proportion of a firm's profits each period. Similar to long-term bonds, the price of equities changes, and we thus multiply by price $\left(\mathrm{p}_{\mathrm{e}}\right)$.

To make the matrix balance vertically (and thus ensure all individual accounts balance), we must include net worth as a balancing item. Net worth is a liability for households, as it is taxed by the government. Firms, on the other hand, accumulate net worth in the form of inventories, which are an asset. Since the government taxes nonequity household wealth, household wealth less the worth of all equities goes into its balance sheet, making all the rows and columns sum to zero. 
Table 2: Transactions-flow Matrix

\begin{tabular}{c|c|c|c|c|c} 
& Households & Firms & Government & Central Bank & $\Sigma$ \\
\hline Government Spending & & $+G$ & $-G$ & & 0 \\
Output & $+W B$ & $-y$ & & 0 \\
Consumption & $-C$ & $+C$ & & \\
Taxes & $-T$ & & $+T$ & \\
Firm profits & $+F_{f}$ & $-F_{f}$ & & 0 \\
Interest on Bonds & $+B L_{h-1}$ & & $-B L_{s}$ & $+B L_{c b-1}$ & 0 \\
Interest on Bills & $+B_{h-1} \cdot r_{b-1}$ & & & $-B_{h-1} \cdot r_{b-1}$ & 0 \\
Changes in Money & $-\Delta H$ & & & $+\Delta H$ & 0 \\
Capital Gains & $+C G$ & $-\Delta p_{e} \cdot e_{d-1}$ & $-\Delta p_{b L} \cdot B L_{h-1}$ & & 0 \\
CB Capital Gains & & & $+C G_{c b}$ & $-C G_{c b}$ & 0 \\
\hline \hline$\Sigma$ & 0 & 0 & 0 & 0 & 0
\end{tabular}

In the transactions-flow matrix, positive entries are credits and negative entries are debits. Because of this change, the signs of entries in the balance sheet might be flipped in related entries in the transactions-flow matrix. This matrix must also have all rows and columns sum to zero, but for slightly different reasons than the balance sheet. Each row represents a transaction and sums to zero as one person's outflow must be another person's inflow. Each column must sum to zero because sectors obviously must "sink" their credit somewhere, even if it's ultimately used to make investments.

Going through the matrix row by row, we start with government spending, which is assumed to be expansionary and to go directly to firms. This is a debit (-G) for the government, and a credit $(+\mathrm{G})$ for firms. Partially funded by government spending, firms produce $y$, which is a debit as they must supply laborers with a wage bill (WB) in return for their services. Some of this money comes back to firms in the form of consumption (C) when households use their money to buy goods and services. Taxes (T) are another household debit that the government collects to fund its own spending.

Firm profits $\left(\mathrm{F}_{\mathrm{f}}\right)$ are assumed to be distributed to households, so firm debits are credits for households. Households and banks receive further infusions of credit via interest on BL and B, at rate $r_{b}$ - both at the government's expense. Since central banks occasionally buy long-term bonds, they have an entry introduced in this equation, too. The per-period repayment on bonds is one currency unit regardless of changes in price, so these terms are not multiplied by $\mathrm{p}_{\mathrm{bL}}$. Some of these credits are then used to accumulate assets in the form of money, so the change in money is recorded as a debit for households. 
To close out the transactions-flow matrix we include the capital gains of both households and the central bank, defined residually for the central bank. Capital gains are a credit for the holders of assets (bonds and equities) and a liability for their issuers, and hence capital gains are in the debit accounts of government and firms specifically. With this, we have an integrated accounting framework.

\section{THE EQUATIONS OF OUR MODEL}

Before discussing results, we present the equations of our model. There are 46 equations and 46 endogenous variables, which can be solved so long as parameters and initial conditions are specified. Many equations are taken from Godley and Lavoie's (2007) Monetary Economics, and specific page references for borrowed equations are contained in the footnotes.

There are four distinct sectors: households, government, firms, and central banks. We eschew representative agents, believing that sectors in the aggregate lack the volition of individuals, and instead use mathematical equations with parameters to model behavior.

Due to the model's girth, there are also no closed form equations for "steady state" values, though given the staggering complexity of the world economy we should not expect these in any case. Before considering the more complex interplay between sectors in our model, we describe each sector's basic behavior.

\subsection{Basic Government Equations}

In our model, governments spend to bolster firm output and tax to finance spending. Government spending $(\mathrm{G})$ is largely exogenous (determined by the parameter $\mathrm{g}$ ), though if the central bank makes any capital gains on its holdings of bonds $\left(\mathrm{CG}_{\mathrm{cb}}\right)$ they will transfer them to the government to fund more spending (Godley and Lavoie 2007, 63): ${ }^{2}$

$$
\mathrm{G} \quad=\mathrm{g}+\mathrm{CG}_{\mathrm{cb}-1}
$$

\footnotetext{
${ }^{2}$ In an SFC framework, all credit must come from somewhere and go somewhere. As the creator of fiat currency, it didn't seem reasonable for the central bank to take advantage of its own capital gains, and as such they are relocated to the government.
} 
In order to finance their spending, the government taxes output $(\mathrm{Y})$ and interest payments at rate $0<\theta<1$ :

$$
\mathrm{T}=\theta\left(\mathrm{Y}+\mathrm{r}_{\mathrm{b}-1} \mathrm{~B}_{\mathrm{h}-1}+\mathrm{BL}_{\mathrm{h}-1}\right)
$$

The reason why long-term bonds held by households $\left(\mathrm{BL}_{\mathrm{h}}\right)$ aren't multiplied by an interest rate, whereas short-term bonds $\left(B_{h}\right)$ are, is that bonds pay back a fixed one currency unit per period rather than paying interest in the traditional sense. As can be seen in equation (41) for disposable income, households bear the brunt of taxation. Although a tax on output is most intuitively understood as a tax on firms, we assumed that firm profits are immediately distributed to households, so the household sector will inevitably feel the full consequences.

\subsection{Basic Central Bank Equations}

In normal situations, the central bank has two policy instruments: setting $\mathrm{r}_{\mathrm{b}}$ and adjusting the prices of long-term bonds. Short-term interest rates are set exogenously by the parameter on the right-hand side:

$$
r_{b}=r^{4}
$$

Long-term government bonds are assumed to be consols, i.e., pieces of paper that entitle their holders to a payment of one currency unit each period. The formula for an interest rate is the per-period payment divided by the asset's cost. It then follows that the long-term rate $\left(\mathrm{r}_{\mathrm{bL}}\right)$ would be:

$$
\mathrm{r}_{\mathrm{bL}}=\frac{1}{p_{b L}}
$$

As per the convention set by Godley and Lavoie (2007), capital gains are not included in the computation of interest rates and instead captured in a separate variable (see equation [31]).

\footnotetext{
${ }^{3}$ Godley and Lavoie $(2007,65)$

${ }^{4}$ Godley and Lavoie $(2007,106)$

${ }^{5}$ Godley and Lavoie $(2007,148)$
} 
The determination of government bond prices is more complex. Of salient importance to the central bank's calculus is the ratio of government bonds times price (TP) and to governmentissued assets (which also includes bills $\mathrm{B}_{\mathrm{h}}$ ):

$$
\mathrm{TP}=\frac{B L_{h-1} p_{b L-1}}{B L_{h-1} p_{b L-1}+B_{h-1}}
$$

The next equation that determines $\mathrm{z}_{1}, \mathrm{z}_{2}$ is meaningless on its own, as $\mathrm{z}_{1}, \mathrm{z}_{2}$ are dummy variables used to construct the price of bonds. The central bank targets a certain ratio of long-term government liabilities to their own liabilities (bills), and they adjust behavior when TP exceeds an upper limit (top) or goes below a lower limit (bot):

$$
\begin{aligned}
z 1= & (0,1) \text { if } T P<\text { bot } \\
z 2 \quad & (1,0) \text { if top }<T P \\
& (0,0) \text { otherwise }
\end{aligned}
$$

In each period, the price of bonds ( $\mathrm{p}_{\mathrm{bL}}$ ) changes according to the values of $\mathrm{z}_{1}, \mathrm{z}_{2}$. If too many long-term bonds are being issued and TP $>$ top, the central bank raises the price to reduce the demand for bonds. On the other hand, if too few bonds are being issued, the central bank takes the opposite approach to increase demand. The parameter $0<\beta<1$ measures how quickly the central bank is willing to make price changes. This is captured in equation (7):

$$
\mathrm{p}_{\mathrm{bL}}=(1+\mathrm{z} 1 \beta-\mathrm{z} 2 \beta) \mathrm{p}_{\mathrm{bL}-1}
$$

We conclude our discussion of the basic central bank equations with a bit of bookkeeping. During quantitative easing regimes, central banks accumulate BL whose prices change over time. Thus we must account for the possibility that the central bank has capital gains:

$$
\mathrm{CG}_{\mathrm{cb}}=\left(\mathrm{p}_{\mathrm{bL}-} \mathrm{p}_{\mathrm{bL}-1}\right) \mathrm{BL}_{\mathrm{cb}-1}
$$

\footnotetext{
${ }^{6}$ Godley and Lavoie $(2007,154)$

${ }^{7}$ Godley and Lavoie $(2007,154)$

${ }^{8}$ Godley and Lavoie $(2007,154)$
} 


\subsection{Firm Sector Equations}

We do not require that output equals demand, but sales (s) obviously cannot exceed demand, and since firms want to accumulate inventories and thus overproduce, we state that demand is at least met. Even in the cases where demand exceeds output, if firms have accumulated inventory they can still meet demand. If our model were taken to certain mathematical extremes, firms might end up with negative inventories, but reasonable parameter spaces preclude such a possibility, so this does not impact future results. Consumption from households (C) and government spending $(\mathrm{G})$ constitute demand:

$$
\mathrm{s}=\mathrm{C}+\mathrm{G}
$$

Since production takes time and firms cannot know what economic fluctuations will do to demand in the interim, they cannot simply produce out of sales plus their desired inventory accumulation. They must instead produce based on expected sales and expected inventories:

$$
\mathrm{s}^{\mathrm{e}}=\beta_{\mathrm{e}} \mathrm{s}_{-1}+\left(1-\beta_{\mathrm{e}}\right) \mathrm{s}_{-1}^{\mathrm{e}}
$$

Firms' expectations are adaptive, based partially on last period's expectations and partially on last period's realized sales; $\beta_{\mathrm{e}}$ captures how reactive firms are to failures in estimation.

Firms accumulate inventory to ensure that even if they underestimate demand they can still sell to all willing buyers. Thus they set an inventory target, which is a fraction $\left(0<\sigma^{\mathrm{T}}<1\right)$ of expected sales. Higher values of $\sigma^{\mathrm{T}}$ would reveal that firms are less certain in their expectations and thus err further on the side of caution. Reaching some target within only one time period is an ambitious goal, however, so firms restrict themselves to closing a proportion $(0<\mu<1)$ of the gap between target and current inventories each period, giving the following equations:

$$
\begin{aligned}
& \operatorname{in}^{\mathrm{T}}=\sigma^{\mathrm{T}} \mathrm{s}^{\mathrm{e}} \\
& \mathrm{in}^{\mathrm{e}}=\mathrm{in}_{-1}+\mu\left(\mathrm{in}^{\mathrm{T}}-\mathrm{in}_{-1}\right)
\end{aligned}
$$

\footnotetext{
${ }^{9}$ Godley and Lavoie $(2007,320)$

${ }^{10}$ Godley and Lavoie $(2007,385)$

${ }^{11}$ Godley and Lavoie $(2007,385)$
} 
If our accounting is to be sound, we must never forget that the firm sector should balance. Output is a debit for firms and sales a credit, but our model allows situations where s is not equal to y (for output y). It naturally follows that there must be some other credit for firms, which we call equities, that are assets entitling their holders to a share of a firm's profit. Equity supply is governed by the equation:

$$
\mathrm{e}_{\mathrm{s}}=\frac{i n v^{e}}{p_{\mathrm{e}-1}^{e}}
$$

Normally, this variable would be equal to the expected change in inventories. Instead, Godley and Lavoie (2007) generally use the supply of a financial instrument to denote all of those instruments that have been issued throughout all periods as opposed to the new supply. Thus, issuance of new equity as well as the validity of old equity is included. As such, firms issue enough equity to finance expected inventory at market prices.

After dealing with expectations, the rest of a firm's decisions are straightforward. They produce output (y) to meet expected sales as well as to close the gap between the inventories they wish to hold at the end of the period and their current inventory holdings:

$$
y=s^{e}+\text { in }^{e}-\text { in }_{-1}
$$

Firms incur production costs in the form of wages. Employment $(\mathrm{N})$ is described by the linear production function,

$$
\mathrm{N}=\mathrm{y} p r^{-1}
$$

where pr is an exogenous productivity parameter and y is output. Firms then pay a wage bill (WB) based on the amount of labor and the exogenous wage rate (W):

$$
\mathrm{WB}=\mathrm{N} \mathrm{W}
$$

\footnotetext{
${ }^{12}$ Godley and Lavoie $(2007,385)$
} 
With production costs and revenues defined, we can now express a firm's profit $\left(\mathrm{F}_{\mathrm{f}}\right)$ :

$$
\mathrm{F}_{\mathrm{f}}=\mathrm{s}-\mathrm{WB}+\Delta \mathrm{in}
$$

To resolve accounting issues, firm profits are assumed to be distributed to households. While simplifying from the real world, it is not absurd to assume that rich firm owners would consume out of a share of their profits.

A ratio $(0<\psi<1)$ of profits are distributed to shareholders and dividends paid on equities $\left(\mathrm{FD}_{\mathrm{f}}\right)$ are then used to compute the rate of return on equities $\left(\mathrm{r}_{\mathrm{k}}\right)$, which will prove essential in specifying a household's portfolio choice:

$$
\begin{aligned}
& \mathrm{FD}_{\mathrm{f}}=\psi \mathrm{F}_{\mathrm{f}} \\
& \mathrm{r}_{\mathrm{k}}=\frac{F D_{f}}{e p_{e} e_{d}}
\end{aligned}
$$

Capital gains are generally included in rates of return, but we relegate this to a capital gains equation, which is added to wealth, as in Godley and Lavoie (2007) (see equations [32] and [35]). Since all firm profits are distributed to households to begin with, $\mathrm{FD}_{\mathrm{f}}$ is not added to household income to avoid double counting. As such, $\mathrm{FD}_{\mathrm{f}}$ is just a useful intermediary variable used to compute the rate of return on equities. While $\mathrm{FD}_{\mathrm{f}}$ might be important in discussions of the distribution of wealth, such discussions are beyond the scope of this model.

\subsection{Basic Household Sector Equations}

Similar to firms, households must make economic decisions before knowing exactly what their disposable income will be. Although households will know the amount of money they currently hold, in the modern economy households routinely make consumption decisions with long-term impacts, whether they be college educations or the purchase of mortgages. As such, households consume out of expected disposable income, invest out of expected wealth, and choose portfolios based on expected rates of return, all of which might prove false.

${ }^{13}$ Godley and Lavoie $(2007,390)$

${ }^{14}$ Godley and Lavoie $(2007,391)$ 
Households estimate their disposable income (YD) by taking a weighted average of last period's realized disposable income and last period's expected disposable income:

$$
\mathrm{YD}^{\mathrm{e}}=\kappa \mathrm{YD}_{-1}+(1-\kappa) \mathrm{YD}_{-1}^{\mathrm{e}}
$$

These adaptive expectations are analogous to the formation of the firm's expectations, with reactivity parameter $0<\kappa<1$.

The household consumption function is a typical Keynesian one, formed by taking the dot product of marginal propensities to consume $\alpha_{1}, \alpha_{2}$ both in the interval $(0,1)$, with expected disposable income $\left(\mathrm{YD}^{\mathrm{e}}\right)$, and last period's wealth $\left(\$ \mathrm{~V}_{-1}\right)$;

$$
\mathrm{C}=\alpha_{1} \mathrm{YD}^{\mathrm{e}}+\alpha_{2} \mathrm{~V}_{-1}
$$

In an SFC framework, all money must come from somewhere and go somewhere, so if there is unspent disposable income it must be held in assets. Of course, households do not know what their end-of-period wealth will be, so they must invest out of expected wealth. Expected wealth is last period's wealth plus expected disposable income less consumption. Expected capital gains are also added, giving,

$$
\mathrm{V}^{\mathrm{e}}=\mathrm{V}_{-1}+\mathrm{YD}^{\mathrm{e}}-\mathrm{C}+\mathrm{CG}^{\mathrm{e}}
$$

for capital gains (CG), defined proximately. In line with households' inability to know the future, they must make investment decisions based on expected rates of return and expected capital gains (which are once again determined by last period's rates of return):

$$
\begin{aligned}
\mathrm{CG}^{\mathrm{e}} & =\mathrm{CG}_{-1} \\
\mathrm{r}_{\mathrm{bL}}^{\mathrm{e}} & =\mathrm{r}_{\mathrm{bL}-1} \\
\mathrm{r}_{\mathrm{k}}^{\mathrm{e}} & =\mathrm{r}_{\mathrm{k}-1}
\end{aligned}
$$

${ }^{15}$ Godley and Lavoie $(2007,393)$

${ }^{16}$ Godley and Lavoie $(2007,165)$ 
With household expectations thus defined, we can now express households' portfolio choices regarding cash, bills, bonds, and equities: ${ }^{17}$

$$
\begin{aligned}
& \mathrm{H}_{\mathrm{d}}=\mathrm{V}^{\mathrm{e}}\left(\lambda_{10}+\lambda_{12} \mathrm{r}_{\mathrm{b}}+\lambda_{13} \mathrm{r}_{{ }_{\mathrm{eL}}}^{\mathrm{e}}+\lambda_{14} \mathrm{r}_{\mathrm{k}}^{\mathrm{e}}\right)+\lambda_{15} \mathrm{YD}^{\mathrm{e}} \\
& \left.\mathrm{B}_{\mathrm{d}}=\mathrm{V}^{\mathrm{e}}\left(\lambda_{20}+\lambda_{22} \mathrm{r}_{\mathrm{b}}+\lambda_{23} \mathrm{r}_{{ }_{b L}}+\lambda_{24} \mathrm{r}_{\mathrm{k}}^{\mathrm{e}}\right)+\lambda_{25} \mathrm{YD}^{\mathrm{e}}\right) \\
& \left.\mathrm{BL}_{\mathrm{d}}=\left(\mathrm{V}^{\mathrm{e}}\left(\lambda_{30}+\lambda_{32} \mathrm{r}_{\mathrm{b}}+\lambda_{33} \mathrm{r}_{{ }_{b L}}+\lambda_{34} \mathrm{r}_{\mathrm{k}}^{\mathrm{e}}\right)+\lambda_{35} \mathrm{YD}^{\mathrm{e}}\right)\right) \mathrm{p}_{\mathrm{bL}}{ }^{-1} \\
& \left.\mathrm{p}_{\mathrm{e}}=\left(\mathrm{V}^{\mathrm{e}}\left(\lambda_{40}+\lambda_{42} \mathrm{r}_{\mathrm{b}}+\lambda_{43} \mathrm{r}_{\mathrm{bL}}+\lambda_{44} \mathrm{r}_{\mathrm{k}}^{\mathrm{e}}\right)+\lambda_{45} \mathrm{YD}^{\mathrm{e}}\right)\right) \mathrm{e}_{\mathrm{d}}^{-1}
\end{aligned}
$$

In line with the models in Godley and Lavoie (2007), households choose portfolios by Tobinesque principals. Portfolio choice is highly parameter dependent, as is clear from the plethora of $\lambda$ 's.

$$
\vec{S}=\left[\begin{array}{l}
\lambda_{10} \\
\lambda_{20} \\
\lambda_{30} \\
\lambda_{40}
\end{array}\right]
$$

describes the default proportions of each asset held by households. Since households can't hold more than their income in various financial instruments, we require that the sum of elements of this vector be one.

The next set of variables is contained in the following reallocation matrix:

$$
R=\left[\begin{array}{cccc}
\lambda_{11} & \lambda_{12} & \lambda_{13} & \lambda_{14} \\
\lambda_{21} & \lambda_{22} & \lambda_{23} & \lambda_{24} \\
\lambda_{31} & \lambda_{32} & \lambda_{33} & \lambda_{34} \\
\lambda_{41} & \lambda_{42} & \lambda_{43} & \lambda_{44}
\end{array}\right]
$$

These $\lambda$ 's track how household portfolios react to changes in the rate of return on various assets. Each row corresponds to the demand function for a different asset, in the order: money, bills, long-term bonds, and equities. This matrix multiplies a vector of the expected rates of return on the four assets,

\footnotetext{
${ }^{17}$ Godley and Lavoie $(2007,146)$
} 


$$
\bar{R}=\left[\begin{array}{c}
0 \\
r_{b} \\
r_{b L}^{e} \\
r_{k}^{e}
\end{array}\right] 18
$$

listed in the same order. Entries on the diagonal are generally positive (as an increase in the rate of return on an asset should increase demand), whereas other entries tend to be negative (when other rates of return are expected to increase, other assets will be less desirable). Lest portfolio reallocation ruin our accounting, we require that all rows of $\mathrm{R}$ sum to zero so that the reallocation of wealth doesn't lead to increased wealth. Furthermore, we require that $\mathrm{R}$ be symmetric. ${ }^{19}$

Finally,

$$
\vec{J}=\left[\begin{array}{l}
\lambda_{15} \\
\lambda_{25} \\
\lambda_{35} \\
\lambda_{45}
\end{array}\right]
$$

captures how portfolios change in response to the disposable-income-to-total-wealth ratio. The portfolios of wealthy and poor households obviously differ, justifying the introduction of extra parameters. The elements of J must sum to zero so that reallocations with respect to greater wealth do not let household portfolios exceed expected wealth.

Thus in matrix algebra with the initial proportional allocation of vector $(\mathbf{S})$, reaction matrix $(\mathbf{R})$, wealth reallocation vector $(\mathbf{J})$, asset vector $(\mathbf{A})$, and expected return vector $(\mathbf{E})$, the last four equations can be rewritten:

$$
\mathbf{A}=V^{\mathrm{e}}\left(\mathbf{S}+\mathbf{R E}+\frac{Y D^{e}}{V^{e}} \mathbf{J}\right)
$$

\footnotetext{
${ }_{18}^{18}$ Money is assumed to have a rate of return of zero.

${ }^{19}$ For a more detailed exposition of the adding up constraints, we refer readers to Godley and Lavoie (2007, ch. 5). 
Before completing our discussion of household portfolios, we must do a bit of bookkeeping with bonds $\left(\mathrm{BL}_{\mathrm{h}}\right)$ and capital gains $(\mathrm{CG})$ :

$$
\begin{aligned}
& B L_{h}=B L_{d}-B L_{d c b} \\
& C G=\left(e p_{e}-e p_{e-1}\right) e_{d-1}+\left(p_{b L}-p_{b L-1}\right) B L_{h-1}
\end{aligned}
$$

where capital gains are defined normally. Here bonds held by households are not exactly equal to bond demand, because in certain situations the central bank will buy bonds $\left(\mathrm{BL}_{\mathrm{dcb}}\right)$ from households as part of a quantitative easing regime (see section 4.6).

With consumption, investment, and capital gains defined, we can now solve for all relevant macroeconomic identities. GDP is typically defined as $\mathrm{C}+\mathrm{G}+\mathrm{I}+\mathrm{X}-\mathrm{M}$, and there is no trade in our model, so we arrive at the expression below. Wealth is defined as last period's wealth $\left(\mathrm{V}_{-1}\right)$ plus net income (YD - C) plus capital gains (CG):

$$
\mathrm{Y}=\mathrm{C}+\mathrm{G}+\mathrm{in}-\mathrm{in}_{-1}
$$

\subsection{Market Clearing Equations}

We are ready to explain new aspects of the model, but we first must complete our accounting. For the sake of simplicity, we assume that markets for equities, short-term bills, and long-term government bonds always clear. Money is supplied to households on demand (see equation [26]), and whenever the central bank buys bonds from households this increases the money

supply, too (which will be explained in the next section). Firms can produce above demand, and any excess production is stored in the form of inventories:

$$
\begin{aligned}
& \mathrm{H}_{\mathrm{h}}=\mathrm{H}_{\mathrm{d}} \\
& \mathrm{V}=\mathrm{V}_{-1}+\mathrm{YD}-\mathrm{C}+\mathrm{CG} \\
& \mathrm{BL}_{\mathrm{s}}=\mathrm{BL}_{\mathrm{h}}+\mathrm{BL}_{\mathrm{cb}} \\
& \mathrm{B}_{\mathrm{s}}=\mathrm{B}_{\mathrm{d}} \\
& \text { in }=\mathrm{in}_{-1}+\mathrm{y}-\mathrm{s} \\
& \mathrm{e}_{\mathrm{d}}=\mathrm{e}_{\mathrm{s}}
\end{aligned}
$$


With supply and demand relations clearly articulated, we turn our attention to quantitative easing and endogenous bubbles.

\subsection{Quantitative Easing Equations}

Quantitative easing is exogenously set. Central banks buy BL $(\gamma)$ each period until the quantitative easing regime's end date. After that, they buy no further bonds. Equation (41) captures this policy's obvious impact on the central bank's balance sheet, while equation (41) states that in exchange for parting with long-term government bonds, YD is boosted by $\mathrm{p}_{b L}$ $\mathrm{BL}_{\mathrm{dcb}}$ :

$$
\begin{aligned}
& \mathrm{BL}_{\mathrm{dcb}}=\min \left(\gamma, \mathrm{BL}_{\mathrm{h}-1}\right) \text { if } \mathrm{t}<\text { duration, } 0 \text { otherwise } \\
& \mathrm{BL}_{\mathrm{cb}}=\mathrm{BL}_{\mathrm{dcb}}+\mathrm{BL}_{\mathrm{cb}-1} \\
& \mathrm{YD}=\mathrm{WB}-\mathrm{T}+\mathrm{r}_{\mathrm{b}-1} \mathrm{~B}_{\mathrm{h}-1}+\mathrm{BL}_{\mathrm{h}-1}+\mathrm{F}_{\mathrm{f}-1}+\mathrm{p}_{\mathrm{bL}} \mathrm{BL}_{\mathrm{dcb}}
\end{aligned}
$$

Wages (WB), taxes (T), interest, and the profits of firms $\left(\mathrm{F}_{\mathrm{f}}\right)$ also determine disposable income. In the determination of bonds demanded by the central bank, we include the minimum function so that the central bank does not buy more bonds from households than they possess.

A significant debate exists as to whether infusions of credit from quantitative easing will be used to consume or just be thrown into financial markets. Rather than directly taking a side in this debate, we capture the real impacts of quantitative easing in disposable income. This may lead to more consumption, but it can also drive the accumulation of wealth that would later be invested (see equation [34]). It is assumed that any interest or capital gains on bonds enjoyed by the central bank are immediately transferred to the government, so quantitative easing does not impact the balance sheets.

For those interested in this paper's connections to quantitative easing regimes pursued by central banks in the wake of the Great Recession, these quantitative easing equations are most closely modeled after the gilt purchasing program of the Bank of England (Joyce et al. 2011). 


\subsection{Endogenous Bubble Equations}

We close out the model by describing its endogenous bubbles. The catalyst of bubble behavior is changes in Tobin's q ratio ${ }^{20}$ (i.e., a market valuation of firms' assets far in excess of their actual collateral):

$$
\mathrm{q}=\frac{e p_{e^{-1}} e_{s^{-1}}}{i n v_{-1}}
$$

If the q ratio goes over an exogenous threshold called "under," the economy begins to panic (captured by P), as it often does when it is realized that stock valuation is far in excess of collateral. If in each period Tobin's q is too low, economic panic is multiplied by the economy's panic rate $(\eta>1)$, resulting in a discrete version of exponential panic. Panic instantly abates when the q ratio rises above "under" again. This takes the functional form:

$$
P=\left\{\begin{array}{c}
1 \text { if } P=0 \wedge \text { und er } \\
P_{-1} \text { nif } P \neq 0 \wedge \text { A under } \\
\text { 0otherwise }
\end{array}\right.
$$

As confidence in equities plummets, worried households become increasingly eager to get rid of toxic assets. To do this, they sell equities $\left(\mathrm{e}_{\mathrm{sh}}\right)$ in the open market at a volume equal to economic panic or, for certain extreme panics, to all of their equity holdings:

$$
\mathrm{e}_{\mathrm{sh}}=\min \left(\mathrm{e}_{\mathrm{d}}, \mathrm{P}\right)
$$

In order to cut their losses, households will sell equities at layoff prices $\left(\mathrm{lp}_{\mathrm{e}}\right)$, which plunge faster for higher values of the behavioral parameter $\phi \in[1,0]$ :

$$
1 p_{e}=(1-\phi) l p_{e-1}
$$

\footnotetext{
${ }^{20}$ Tobin's q ratio is canonically defined as market valuation over real assets.
} 
The impact of layoffs on market prices is captured by our last endogenous variable, the effective price of equities $\left(\mathrm{ep}_{\mathrm{e}}\right)$. Effective price is computed by a weighted average of the price charged for equities by firms and the price charged by desperate households:

$$
\mathrm{ep}_{\mathrm{e}}=\frac{e_{s h} l p_{e}}{e_{d}}+p_{\mathrm{e}}\left(1-\frac{e_{s h}}{e_{d}}\right)
$$

Whenever equities change hands within the household sector, it is not recorded on the transactions-flow matrix, as these are intrasectoral transactions.

Over time, households will supply more equities for a lower price, and the downward effect on price will raise Tobin's q and end the bubble. Readers may wonder why we decided to model panic and the concomitant plunge in prices exponentially. This model is sufficiently theoretical that regression analysis of stock market data around major bubbles did not seem worthwhilemost important to us was finding some mathematical relation that captures the precipitous nature of bubbles.

With this, we have an equation for every endogenous variable. Given appropriate parameters and initial conditions, we can now solve the model.

\subsection{On the Conspicuous Absence of Inflation}

Readers will note that in this model there is no price inflation (outside of the particular cases of equities and long-term government bonds). This seems out of place in a model exploring the impacts of an increase in the money supply. Remember that financial markets are more volatile than real markets, and the time scale where asset inflation is relevant is far smaller than that in which macroeconomic price inflation is relevant. As a model particularly focused on realfinancial linkages, the time periods should be thought of as shorter than in most other macroeconomic models. With this in mind, assuming price-level stability is reasonable.

The shorter time interval we are working in should qualify interpretations of any "equilibrium" behavior that's exhibited, as steady states are only truly steady in the short run this model focuses upon. 


\section{RESULTS}

In this section we present the results of the model when run. Before proceeding, there are two methodological notes to be made. First, since analytically solving a system of 46 difference equations (not all linear) is impractical, we only present the results of different computer simulations. While this will no doubt make some readers uncomfortable, we have no preference for explicit formulas, believing that if the economy could be captured in such a simple form our discipline would consistently make accurate predictions. Our model is also sufficiently theoretical that the figures produced should not be viewed as empirical predictions of any kind - rather, we concern ourselves herein with the qualitative impacts of policy and behavioral changes.

Due to the large number of parameters and initial conditions our model requires, we will not be testing all of them. We instead focus on $\alpha_{1}$ (household propensity to consume out of income), $\gamma$ (the size of central bank bond buyouts) and duration - which together determine quantitative easing programs - and $\mu$, a firm reactivity parameter that proved to be vitally important. All other initial conditions and parameters are held constant in our simulations. See section A.1 for a specification of other parameters. ${ }^{21}$

\subsection{Comparing No Quantitative Easing and Quantitative Easing with a Low Propensity to Consume Out of Income $\left(\alpha_{1}=.3\right)$}

Our exploration of the model's properties begins with an evaluation of macroeconomic performance in an economy with a low propensity to consume out of income. All parameters are held constant across simulations, except for the quantitative easing parameters duration, $\gamma$ (see equation [40]), which are $(0,0)$ in the no quantitative easing case and $(10,0.5)$ in the others. We first consider consumption in the short run and the long-run GDP without quantitative easing.

\footnotetext{
${ }^{21}$ Since our model is built off of chapters 5 and 11 of Godley and Lavoie (2007), readers should see those chapters if they are interested in other properties of this line of models.
} 
Figure 1: Consumption without Quantitative Easing

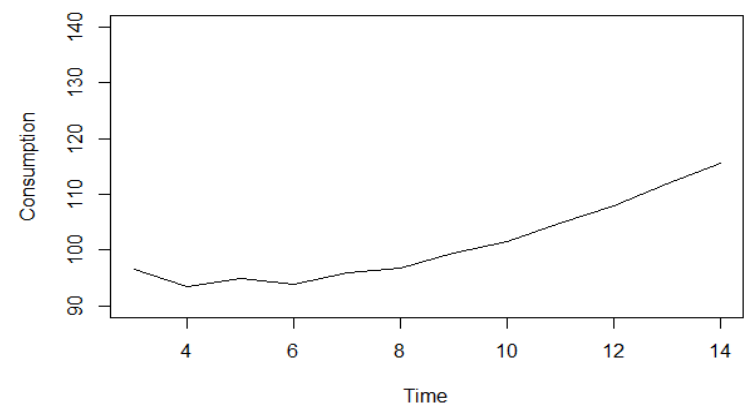

Figure 2: Long-run GDP without Quantitative Easing

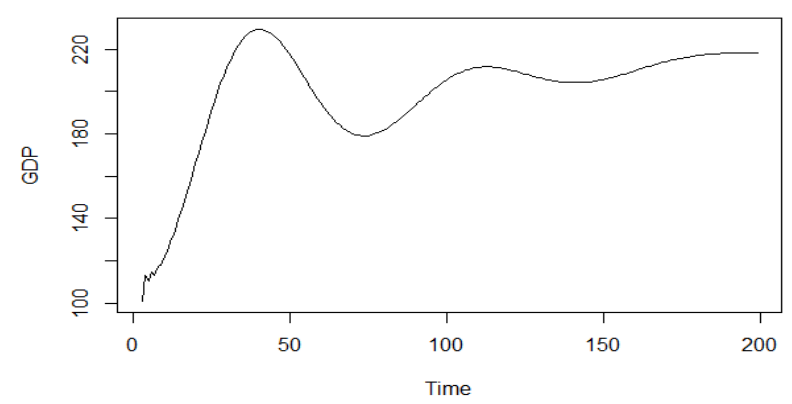

Figure 1 is not interesting in and of itself, and is mainly used for future comparison with consumption under quantitative easing. Figure 2 displays a gradual adjustment to a steady state over time, with the economy overheating before its behavior normalizes. As shown below, the introduction of quantitative easing to our model does not fundamentally alter the model's longterm behavior.

Figure 3: Consumption with Quantitative Easing

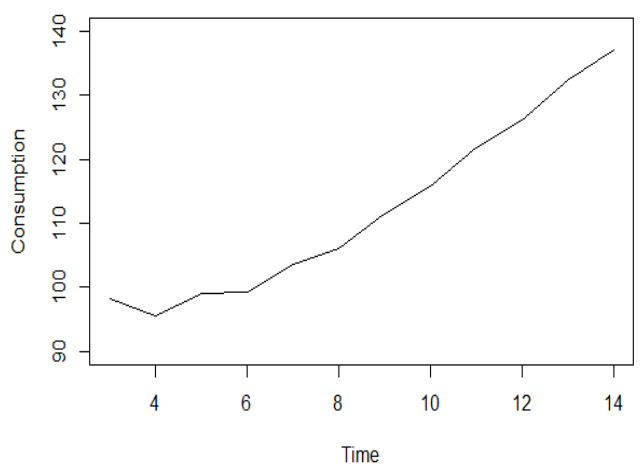


Figure 4: Long-run GDP with Quantitative Easing

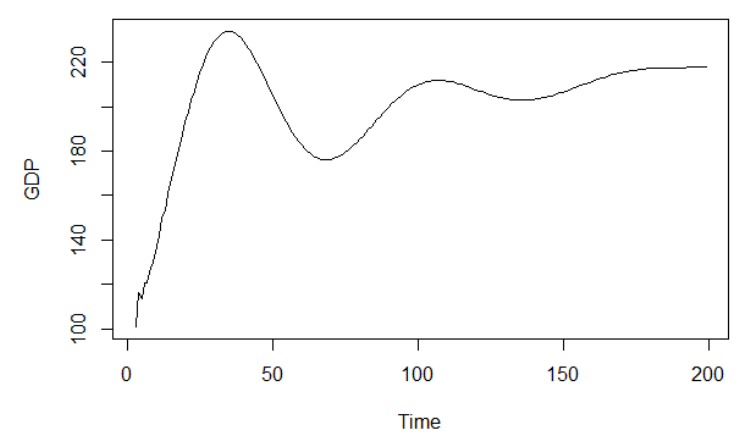

That being said, there are nontrivial quantitative differences between figures 1 and 2 and figures 3 and 4 . In the short run, consumption is noticeably boosted by quantitative easing, going around 15 currency units higher in figure 3 than in figure 1. In the longer run, these disparities are smoothed, as the two economies have nearly identical peaks and troughs in figures 2 and 4 . The quantitative easing does, however, speed up this cyclical boom-bust behavior. This is demonstrated by figures 5 and 6, which measure economic panic (P) (described in equation [44]).

Figure 5: Economic Panic without Quantitative Easing

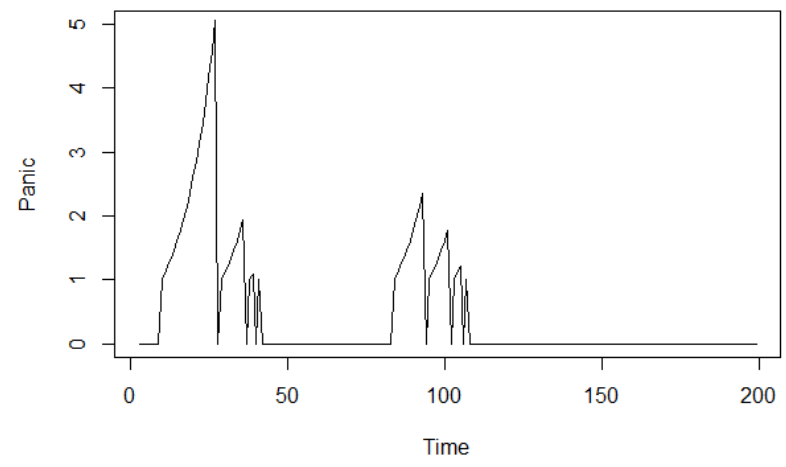


Figure 6: Economic Panic with Quantitative Easing

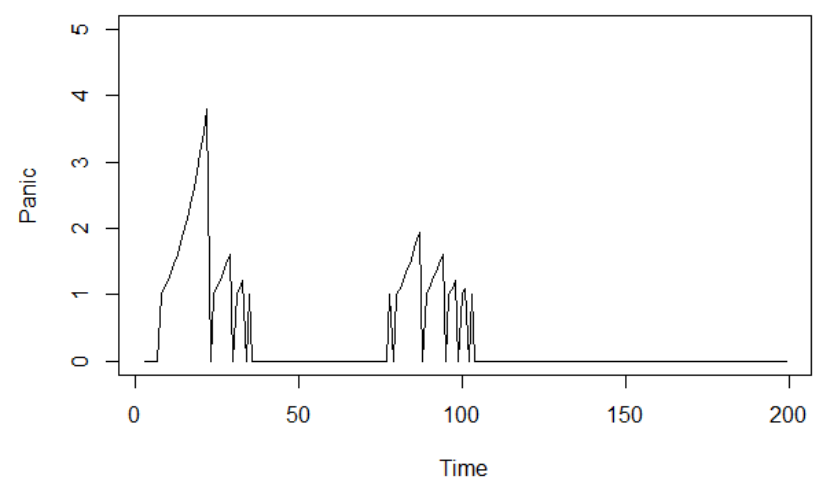

\subsection{A Repeat with High Propensity to Consume Out of Income $\left(\alpha_{1}=.4\right)$}

Similar "phase shift" behavior is observed when the propensity to consume out of income is high, but it acts in the opposite direction, as shown below:

Figure 7: GDP without Quantitative Easing

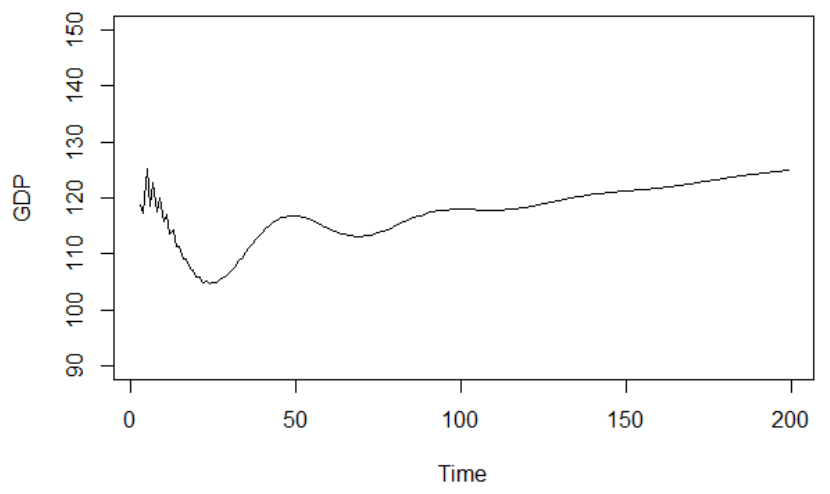

Figure 8: GDP with Quantitative Easing

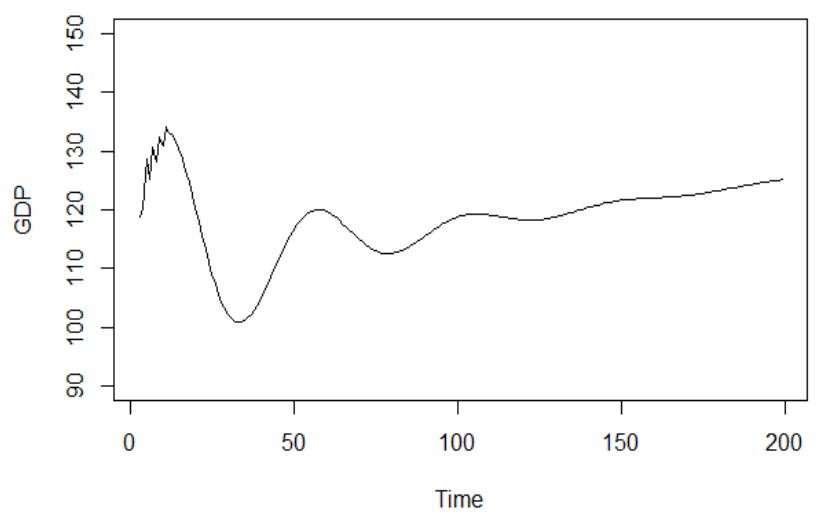


Note that the specifications of duration, $\gamma$ are the same as in the last subsection. Most immediately alarming is how GDP is far lower with high consumption out of income than with low consumption. While this is illogical if we only consider $Y=C+G+I$, remember that we are modeling an economy moving through time. Thus, if households consume more, it will reduce their wealth going into the next period (see equation [34]), which will in turn constrain investment and cripple the longer-term march of economic progress.

As mentioned before, the "phase shift" impact of quantitative easing now pushes GDP rightwards with respect to time. For the model demonstrating a high propensity to consume out of income, quantitative easing also has a small impact on trough and peak values, too- the low points of the economy with quantitative easing are slightly lower, and its highs are slightly higher. Therefore, in high consumption periods quantitative easing is moderately procyclical. Strangely enough, this does not correspond to any difference in economic panic, which remains fixed in both simulations:

\section{Figure 9: Economic Panic without Quantitative Easing}

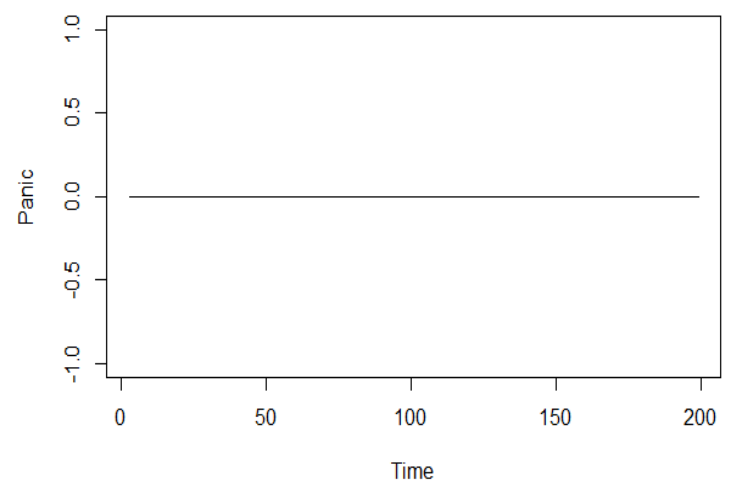

Figure 10: Economic Panic with Quantitative Easing

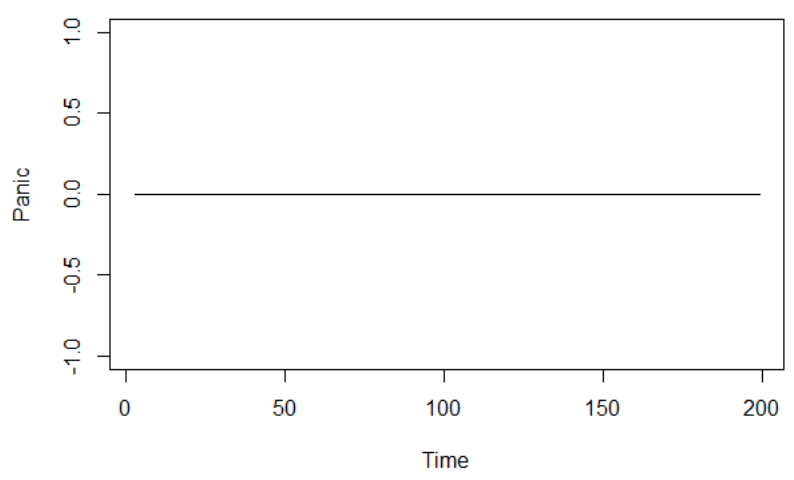


In our model, panics are caused by an overvaluation of equities, symbolized by a q ratio above certain bounds (see section 4.7). It should not surprise us that in a low-investment economy equity markets do not swell out of proportion, as higher consumption will lead firms to accumulate less inventory and thus issue fewer equities, essentially removing the possibility that assets could become overvalued. Nevertheless, the way the economy continues to fluctuate without panic demands an explanation. This is provided in the next subsection.

\subsection{Another Source of Instability}

The parameter $\mu$ captures the rate at which firms try to bridge gaps between current and target inventories. In the past two simulations, $\mu$ was equal to 0.7 . Since expected inventories is a term in the output function (see equations [11], [12], and [14]), a firm's ability to nimbly adjust inventories to changing economic headwinds is a determinant of how well output matches demand. Consider, then, a simulation with $\mu=0.65$ and a propensity to consume out of income $\left(\alpha_{1}\right)=0.3$ :

\section{Figure 11: GDP with Reduced Reactions}

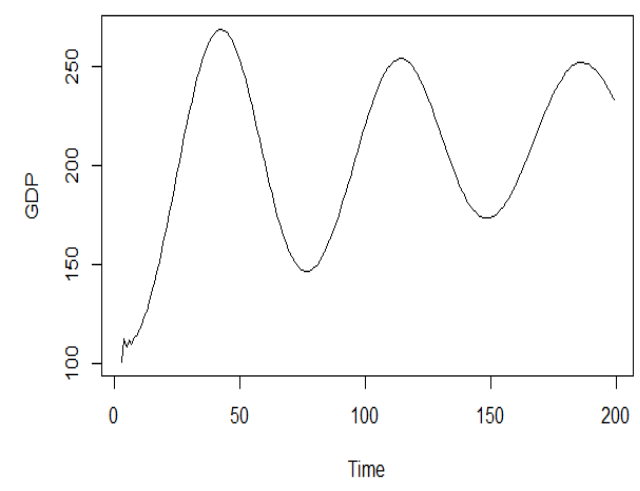

\section{Figure 12: Economic Panic with Reduced Reactions}

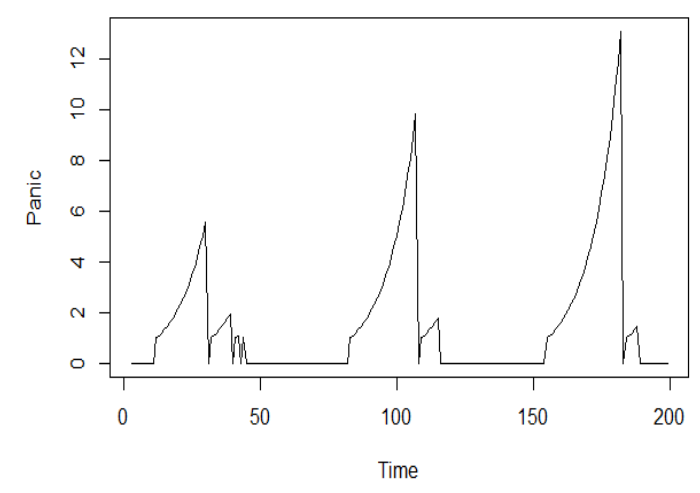


When compared to earlier simulations, it is clear that the peak-trough differences in figure 11 are abnormally large. Although economic panic is similarly high in figure 5, the large differences in cyclical behavior suggest the change in $\mu$ is responsible. It should not surprise us that the misalignment of expectations captured by $\mu$ destabilize the economy. What is surprising, however, is that throughout our simulations, quantitative easing acted as little more than an economic phase shift.

\section{CONCLUSION}

This paper's findings are contrary to those of monetary theorists who support static policy rules, such as the Taylor rule. Quantitative easing's outcomes are parameter dependent, with economies less prone to consumption out of income merely being pushed forward in the schedule of rise and fall, whereas economies with greater consumption experienced minor procyclical effects. The utility of quantitative easing is thus heavily parameter dependent and not easily encapsulated in simple statements.

The one thing that stood out, however, was how little quantitative easing fed economic panic. While the aforementioned "phase shift" in economic outcomes affected panic (as well as all other indicators), it did little to change peak panic levels. Propensity to consume out of income and the reaction rate of firms to changes in target inventories proved far more consequential predictors of stock market panic. Furthermore, when summed up across the long run, quantitative easing was almost irrelevant, shifting the timeline of events, but utterly powerless to change their course.

Due to the simplifications that any model must make, our results are not incontrovertible. If taken at face value, however, these simulations imply that quantitative easing has little effect at the level of macroeconomic indicators. It was neither expansionary nor deeply harmful, but merely ineffectual. Nevertheless, there are other avenues by which quantitative easing might be harmful that we have omitted from the model, and we thus hope further research is done to see if quantitative easing causes harm in other areas. 


\section{REFERENCES}

Bullard, James. 2010. "Three Lessons for Monetary Policy from the Panic of 2008." Federal Reserve Bank of St Louis Review 93: 155-63.

Eggertsson, Gauti B., and Michael Woodford. 2003. "The Zero Bound on Interest Rates and Optimal Monetary Policy.” Brookings Papers on Economic Activity No. 1:2003. Washington, DC: The Brookings Institution.

Fratzscher, Marcel, Mario Lo Duca, and Roland Straub. 2013. "On the International Spillovers of US Quantitative Easing.” ECB Working Paper 1557. Frankfurt: European Central Bank.

Fujii, M., and M. Kawai. 2010. “Lessons from Japan’s Banking Crisis, 1991-2005.” ADBI Working Paper 222. Tokyo: Asian Development Bank Institute.

Godley, W., and M. Lavoie. 2007. Monetary Economics. Basingstoke, UK: Palgrave Macmillan.

Hirano, Tomohiro, and Noriyuki Yanagawa. 2014. "Asset Bubbles, Endogenous Growth, and Financial Frictions.” Unpublished manuscript. Tokyo: Institute of Economic Research, Hitotsubashi University.

Joyce, Michael A., Ana Lasaosa, Ibrahim Stevens, and Matthew Tong. 2013. "The Financial Market Impact of Quantitative Easing in the United Kingdom." International Journal of Central Banking 7(3): 113-61.

Mehrling, Perry, Zoltan Pozsar, James Sweeney, and Daniel H. Neilson. 2013. "Bagehot was a Shadow Banker: Shadow Banking, Central Banking, and the Future of Global Finance." Unpublished manuscript, November 5. Available at: http://dx.doi.org/10.2139/ssrn.2232016

Minsky, Hyman P. 1992. “The Financial Instability Hypothesis.” Levy Institute Working Paper 74. Annandale-on-Hudson, NY: Levy Economics Institute of Bard College.

Owusu-Ansah, Yaw. 2013. "What Went Wrong? Examining Moody's Rated CDO Data." Columbia Working Papers 1. New York: Colombia University.

Palley, Thomas I. 2011. "Quantitative Easing: A Keynesian Critique.” PERI Working Paper Series 252. Amherst, MA: Political Economy Research Institute.

Taylor, John B. 1993. "Discretion vs. Policy Rules in Practice.” Carnegie Rochester Conference Series on Public Policy 39. Stanford, CA: Stanford University. 


\section{APPENDICES}

\section{A.1. Parameters}

1. $\gamma$ is the amount of bonds the central bank buys each period of quantitative easing.

2. $\sigma^{\mathrm{T}}=0.5$ is the target-inventories-to-sales ratio.

3. $p r=1.06$ is labor productivity.

4. duration is the number of time periods quantitative easing lasts.

$5 . \phi=.04$ is the fraction of the usual cost households sell equities at during panics.

6. $\eta=1.1$ is the economic panic rate.

7. under $=1.0$ is the highest Tobin's q ratio can go before households panic.

8. $\mu$ is how quickly firms try to approach target inventories.

9. $\theta=0.2$ is the tax rate.

10. $\alpha_{1}, \alpha_{2}=\mathrm{n} / \mathrm{a}, 0.4$ is the propensities to consume out of income and/or wealth.

11.

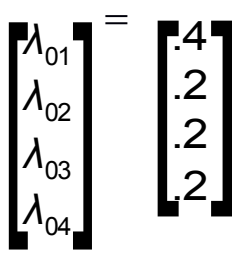

are the proportions of four assets (money, bills, long-term bonds, equities) that households seek to hold - entries must sum to unity.

12.

$$
\left[\begin{array}{llll}
\lambda_{11} & \lambda_{21} & \lambda_{31} & \lambda_{41} \\
\lambda_{12} & \lambda_{22} & \lambda_{32} & \lambda_{42} \\
\lambda_{13} & \lambda_{23} & \lambda_{33} & \lambda_{34} \\
\lambda_{14} & \lambda_{24} & \lambda_{34} & \lambda_{44}
\end{array}\right]=\left[\begin{array}{cccc}
.4 & -.2 & -.1 & -.1 \\
-.2 & .4 & -.1 & -.1 \\
-.1 & -.1 & .4 & -.2 \\
-.1 & -.1 & -.2 & .4
\end{array}\right]
$$

are the portfolio reactions to the rates of returns on assets. Rows and columns must sum to zero, only diagonal entries should be positive, and the matrix must be symmetric. 
13. $\left[\begin{array}{l}\lambda_{51} \\ \lambda_{52} \\ \lambda_{53} \\ \lambda_{54}\end{array}\right]=\left[\begin{array}{l}.25 \\ .25 \\ .25 \\ .25\end{array}\right]$

is how households adapt their portfolio choices in response to rising disposable income.

14. $\beta_{\mathrm{e}}=0.79$ is the rate of reactions of firms to faulty expectations in the previous period.

15. $\beta=0$ is how fast the price of long-term bonds is adjusted.

16. $($ top, bot $)=(0.5,0.9)$ are the limits of TP (target portfolios) (see equation [5]) at which bond rates are changed

17. $\psi=0.2$ is the proportion of profits distributed as dividends to households.

18. $\mathrm{g}=20$ is baseline government spending.

19. $r=0.01$ is the short-term interest rate.

$20 . \mathrm{W}=1$ is the wage rate.

$21 . \kappa=0.3$ is households' reactivity to mistaken expectations. 


\section{A.2. Equations}

$$
\begin{aligned}
\mathrm{G}= & \mathrm{g}+\mathrm{CG}_{\mathrm{cb}-1} \\
\mathrm{~T}= & \theta\left(\mathrm{Y}+\mathrm{r}_{\mathrm{b}-1} \mathrm{~B}_{\mathrm{h}-1}+\mathrm{BL}_{\mathrm{h}-1}\right) \\
\mathrm{r}_{\mathrm{b}}= & \mathrm{r} \\
\mathrm{r}_{\mathrm{bL}}= & \frac{1}{p_{b L}} \\
\mathrm{TP}= & \frac{B L_{h-1} p_{b L-1}}{B L_{h-1} p_{b L-1}+B_{h-1}} \\
= & (0,1) \text { ifTP }<\text { bot } \\
& \quad(1,0) \text { iftop }<T P \\
& \quad(0,0) \text { otherwise }
\end{aligned}
$$

$$
\begin{aligned}
& \mathrm{p}_{\mathrm{bL}}=(1+\mathrm{z} 1 \beta-\mathrm{z} 2 \beta) \mathrm{p}_{\mathrm{bL}-1} \\
& \mathrm{CG}_{\mathrm{cb}}=\left(\mathrm{p}_{\mathrm{bL}-} \mathrm{p}_{\mathrm{bL}-1}\right) \mathrm{BL}_{\mathrm{cb}-1} \\
& \mathrm{~s}=\mathrm{C}+\mathrm{G} \\
& \mathrm{s}^{\mathrm{e}}=\beta_{\mathrm{e}} \mathrm{S}_{-1}+\left(1-\beta_{\mathrm{e}}\right) \mathrm{s}_{-1}^{\mathrm{e}} \\
& \text { in }^{\mathrm{T}}=\sigma^{\mathrm{T}} \mathrm{s}^{\mathrm{e}} \\
& \mathrm{in}^{\mathrm{e}}=\mathrm{in}_{-1}+\mu\left(\mathrm{in}^{\mathrm{T}}-\mathrm{in}_{-1}\right) \\
& \mathrm{e}_{\mathrm{s}}=\frac{i n v^{e}}{p_{e-1}^{e}} \\
& \mathrm{y}=\mathrm{s}^{\mathrm{e}}+\mathrm{in}^{\mathrm{e}}-\mathrm{in}_{-1} \\
& \mathrm{~N}=\mathrm{y} p r^{-1} \\
& \mathrm{WB}=\mathrm{N} \mathrm{W} \\
& \mathrm{F}_{\mathrm{f}}=\mathrm{s}-\mathrm{WB}+\Delta \mathrm{in} \\
& \mathrm{FD}_{\mathrm{f}}=\psi \mathrm{F}_{\mathrm{f}} \\
& \mathrm{r}_{\mathrm{k}}=\frac{F D_{f}}{e p_{e} e_{d}} \\
& \mathrm{YD}^{\mathrm{e}}=\kappa \mathrm{YD}_{-1}+(1-\kappa) \mathrm{YD}_{-1}^{\mathrm{e}} \\
& \mathrm{C}=\alpha_{1} \mathrm{YD}^{\mathrm{e}}+\alpha_{2} \mathrm{~V}_{-1} \\
& \mathrm{~V}^{\mathrm{e}}=\mathrm{V}_{-1}+\mathrm{YD}^{\mathrm{e}}-\mathrm{C}+\mathrm{CG}^{\mathrm{e}} \\
& \mathrm{CG}^{\mathrm{e}}=\mathrm{CG}_{-1}
\end{aligned}
$$




$$
\begin{aligned}
& r_{b L}^{e_{b L}}=r_{b L-1} \\
& r_{k}^{e_{k}}=r_{k-1}
\end{aligned}
$$

$$
\begin{aligned}
& {\left[\begin{array}{c}
H_{d} \\
B_{d} \\
B L_{d} p_{b L} \\
e_{d} p_{e}
\end{array}=i \quad\left[\begin{array}{l}
\lambda_{01} \\
\lambda_{02} \\
\lambda_{03} \\
\lambda_{04}
\end{array}\right]+\mathrm{V}^{\mathrm{e}}\left[\begin{array}{llll}
\lambda_{11} & \lambda_{21} & \lambda_{31} & \lambda_{41} \\
\lambda_{12} & \lambda_{22} & \lambda_{32} & \lambda_{42} \\
\lambda_{13} & \lambda_{23} & \lambda_{33} & \lambda_{34} \\
\lambda_{14} & \lambda_{24} & \lambda_{34} & \lambda_{44}
\end{array}\right]\left[\begin{array}{c}
0 \\
r_{b} \\
r_{b L}^{e} \\
r_{k}^{e}
\end{array}\right]+\mathrm{YD}^{\mathrm{e}}\left[\begin{array}{l}
\lambda_{51} \\
\lambda_{52} \\
\lambda_{53} \\
\lambda_{54}
\end{array}\right](26-29)\right.} \\
& \mathrm{BL}_{\mathrm{h}}=\mathrm{BL}_{\mathrm{d}}-\mathrm{BL}_{\mathrm{dcb}} \\
& \mathrm{CG}=\left(\mathrm{ep}_{\mathrm{e}}-\mathrm{ep}_{\mathrm{e}-1}\right) \mathrm{e}_{\mathrm{d}-1}+\left(\mathrm{p}_{\mathrm{bL}}-\mathrm{p}_{\mathrm{bL}-1}\right) \mathrm{BL}_{\mathrm{h}-1} \\
& \mathrm{Y}=\mathrm{C}+\mathrm{G}+\text { in }- \text { in }_{-1} \\
& \mathrm{H}_{\mathrm{h}}=\mathrm{H}_{\mathrm{d}} \\
& \mathrm{V}=\mathrm{V}_{-1}+\mathrm{YD}-\mathrm{C}+\mathrm{CG} \\
& \mathrm{BL}_{\mathrm{s}}=\mathrm{BL}_{\mathrm{h}}+\mathrm{BL}_{\mathrm{cb}} \\
& \mathrm{B}_{\mathrm{s}}=\mathrm{B}_{\mathrm{d}} \\
& \text { in }=\text { in }_{-1}+\mathrm{y}-\mathrm{s} \\
& \mathrm{e}_{\mathrm{d}}=\mathrm{e}_{\mathrm{s}} \\
& \mathrm{BL}_{\mathrm{dcb}}=\min \left(\gamma, \mathrm{BL}_{\mathrm{h}-1}\right) \text { if } \mathrm{t}<\text { duration, } 0 \text { otherwise } \\
& \mathrm{BL}_{\mathrm{cb}}=\mathrm{BL}_{\mathrm{dcb}}+\mathrm{BL}_{\mathrm{cb}-1} \\
& \mathrm{YD}=\mathrm{WB}-\mathrm{T}+\mathrm{r}_{\mathrm{b}-1} \mathrm{~B}_{\mathrm{h}-1}+\mathrm{BL}_{\mathrm{h}-1}+\mathrm{F}_{\mathrm{f}-1}+\mathrm{p}_{\mathrm{bL}} \mathrm{BL}_{\mathrm{dcb}} \\
& \mathrm{q}=\frac{\Theta p_{e^{-1}} e_{s^{-1}}}{i n v_{-1}} \\
& P=\left\{\begin{array}{c}
1 \text { if } P=0 \wedge \text { u under } \\
P_{-1} \text { nif } P \neq 0 \wedge q<\text { under } \\
\text { Ootherwise }
\end{array}\right. \\
& \mathrm{e}_{\mathrm{sh}}=\min \left(\mathrm{e}_{\mathrm{d}}, \mathrm{P}\right) \\
& 1 p_{\mathrm{e}}=(1-\phi) l \mathrm{p}_{\mathrm{e}-1} \\
& \mathrm{ep}_{\mathrm{e}}=\frac{e_{s h} I p_{e}}{e_{d}}+p_{\mathrm{e}}\left(1-\frac{e_{s h}}{e_{d}}\right)
\end{aligned}
$$

